Www.jmscr.igmpublication.org

Impact Factor (SJIF): 6.379

Index Copernicus Value: 79.54

ISSN (e)-2347-176x ISSN (p) 2455-0450

crossrefDOI: https://dx.doi.org/10.18535/jmscr/v7i1.68

Journal Of Medical Science And Clinical Research

IGM Publication

An Official Publication of IGM Publication

\title{
Histopathological pattern of abnormal uterine bleeding in endometrial biopsies in reproductive age group at tertiary SKIMS Trust hospital
}

\author{
Authors \\ Dr Shazia Nisar ${ }^{*}$, Dr Shabnam Ara ${ }^{2}$, Dr Shahid Banday ${ }^{3}$ \\ ${ }^{1,2}$ Department of Obstertrics and Gynaecology, Maternity Hospital, SKIMS, Jammu Kashmir, India \\ ${ }^{3}$ Department of Pediatric Surgery SKIMS, Jammu Kashmir, India \\ *Corresponding Author \\ Dr Shazia Nisar \\ Senior Resident, Obstertrics and Gynaecology, Maternity Hospital, SKIMS, Jammu Kashmir, India \\ Email: bandaysajid89@gmail.com
}

\begin{abstract}
Introduction: Abnormal uterine bleeding is a common presenting complaint in gynaecology out patient department. Histopathological evaluation of the endometrial samples plays a significant role in the diagnosis of abnormal uterine bleeding. It occurs in 9-14\% of women between menarche and menopause, significantly impacting quality of life and imposing financial burden

Aims and Objective: To ascertain types and frequencies of various types of histopathological changes of the endometrium in patients of reproductive age group with abnormal uterine bleeding attending OPD at SKIMS Trust hospital.

Materials and Methods: In this prospective study [Jan 2016-jan 2017] a total number of 200 endometrial biopsies were obtained by dilatation and curettage from patients with abnormal uterine bleeding in age group 18-50 years attending SKIMS Trust hospital OPD.

Results: out of 200 patients, 20 were in age group of 18-28,30 were in age group of 29-38 while as 150 were in age group of 39-50.Duration of symptoms was 0-2 months in 10 patients while it was 3-6 months in 140 patients and 7-12 months in 50 patients. PROLIFERATIVE type of histology was the most common [40\%].

Conclusion: Anovulation is commonest cause of AUB in reproductive age group and study of histopathological changes of endometrium is very important in management of AUB.

Keywords: $A U B=$ Abnormal uterine bleeding ; DUB=Dysfunction uterine bleeding.
\end{abstract}

\section{Introduction}

AUB is one of the most common problems in women of all ages especially those in the perimenopausal age group ${ }^{1}$. The abnormal bleeding can be caused by a wide variety of disorders and it is one of the commonest complaints leading to endometrial sampling. It may represent a normal physiological state, and observation alone may be warranted. Alternatively, the bleeding can be a sign of a serious underlying condition necessitating aggressive treatment ${ }^{2}$ Dilatation and curettage is a useful and cost effective method of 
detecting intrauterine pathologies and very few lesionsescape detection ${ }^{3}$. Normal menstrual cycle is exquisitely controlled by the rise and fall of pituitary and ovarian hormones which is executed by proper timing of hormone release in both absolute and relative amounts. Abnormalities in this system result in abnormal uterine bleeding. Normal menstrual cycle duration is 24-38 days. Average flow lasts for 4-6 days. Average loss of blood is $30 \mathrm{ml}$. Blood loss greater than $80 \mathrm{ml}$ is abnormal which results in anemia. Prolonged flow is that which lasts for greater than 8 days ${ }^{4}$. Dysfunctional uterine bleeding (DUB) is a complex symptomatology which includes all conditions of abnormal uterine bleeding in absence of pregnancy, neoplasm, infection, intrauterine lesion ${ }^{5}$. Acute DUB is defined as an episode of bleeding in a woman of reproductive age who is not pregnant, that in the opinion of the provider is of sufficient quantity to require immediate intervention to prevent further blood loss. Chronic DUB from the uterine corpus i.e. abnormal in duration, volume and or frequency and has been present for the majority of the last 6 months. Endometrial aspiration of is a safe simple and reliable technique without any complications. So we used it as a safe and reliable outpatient procedure with minimal discomfort to the patient ${ }^{6}$. Various causes of DUB in non-gravid women in reproductive year classification5 - Polyp, adenomyosis, leiomyoma, malignancy, and hyperplasia, coagulopathy, ovulatory disorders of endometrium, iatrogenic and not classified. The causes of bleeding in elderly women are hormonal and more importantly local pathology including malignancy, benign tumours and infections ${ }^{7}$.

The main purpose of endometrial sampling is to exclude local intrauterine pathology and to obtain endometrium for study of its hormone responses. Curettage is mainly diagnostic, sometimes curative, especially in cases of irregular shedding. It has no value in treatment of polymenorrheal Pathology of DUB - Unopposed estrogen increases vascularity of endometrial tissue with relatively scant stroma. The glands have back to back appearance. The resultant endometrium is fragile. In patients of AUB above 30 years presenting with anovulation endometrial aspiration is indicated because of risk of hyperplasia and neoplasia ${ }^{8}$.

\section{Aims and Objective}

Histopahological pattern of endometrium in dysfunction utrerine bleeding in a hospital based sample in a reproductive age group and correlation with age distribution and clinical findins

\section{Material \& Methods}

This was a hospital based prospective study performed in the outpatient department of gynae and obstetric trust hospital, sher-i-kashmir institute of medical sciences soura,it is a 700 beded hospital. The study was performed for a period of 1 year [jan 2016-jan 2017] and 200 patients were included in the study. All patients in the age group of 18 to 50 with vaginal bleeding for more than 8days or more or soaking pads more than 5 or ultrasound evidence of endometrial thickness more than 5mm. Patients with a gestational cause, hemostatic disorders, isolated cervical or vaginal pathology, and leiomyoma excluded. Relevant clinical data regarding age, pattern and duration of abnormal bleeding, menstrual history, obstetric history, use of exogenous hormones, physical and gynecological examination findings, lab investigation results, and sonological findings were collected. Patients were categorised into age groups of 18 to 20, 29 to 38 and 39-50years. Diagnostic curettage was done for patients with abnormal uterine bleeding of any pattern at age over 40 years or less than 40 years with failure to response to medical treatment or with risk factors for endometrial carcinoma such as obesity, polycystic ovarian disease, tamoxifen therapy and family history of endometrial carcinoma. The tissues obtained by curettage were examined in the Pathology Department of Sher-iKashmir Institute of Medical Sciences Soura, where it was first fixed in (10\%) neutral formalin. 
The specimens were routinely processed and 45microne thick sections were cut from paraffin blocks and stained with routine haematoxylin and eosin stains and the patterns of uterine histopathological changes identified and classified according to age groups

\section{Results}

Tabulated and expressed as percentages

Table 1: DUB according to age groups

\begin{tabular}{|l|c|c|}
\hline $\begin{array}{l}\text { Age groups and Age } \\
\text { (Yrs) }\end{array}$ & $\begin{array}{c}\text { No of cases } \\
\text { with DUB }\end{array}$ & $\begin{array}{c}\text { Percentage } \\
\text { (\%) }\end{array}$ \\
\hline 18 to 28 & 20 & 10 \\
\hline 29 to 38 & 30 & 15 \\
\hline 39 to 50 & 150 & 75 \\
\hline & 200 & 100 \\
\hline
\end{tabular}

DUB was found to be more in perimenopausal period $(75 \%)$

Table 2: duration of symptoms

\begin{tabular}{|l|c|c|}
\hline $\begin{array}{l}\text { Duration of } \\
\text { symptoms in months }\end{array}$ & No of cases & Percentage \\
\hline 0 to 2 & 10 & 5 \\
\hline 3 to 6 & 140 & 70 \\
\hline 7 to 12 & 50 & 25 \\
\hline & 200 & 100 \\
\hline
\end{tabular}

3 to 6 month duration of symptoms predominate
Table 3: Various bleeding patterns in DUB

\begin{tabular}{|l|c|c|}
\hline Bleeding Pattern & No of cases & Percentage (\%) \\
\hline Menorrhagia & 92 & 46 \\
\hline Polymenorrhagia & 6 & 3 \\
\hline Polymenorrhoea & 48 & 24 \\
\hline Metrorrhagia & 24 & 12 \\
\hline Continuous Bleeding & 30 & 15 \\
\hline & 200 & 100 \\
\hline
\end{tabular}

Most common type of bleeding in DUB was found to be menorrhagia followed by polymenorrhea.

Table 4: Histopathological pattern in DUB

\begin{tabular}{|l|c|c|}
\hline Endometrial changes & No of cases & Percentage (\%) \\
\hline Proliferative phase & 80 & 40 \\
\hline Secretory phase & 40 & 20 \\
\hline atrophic & 16 & 8 \\
\hline Irregular shedding & 16 & 8 \\
\hline Irregular ripening & 36 & 18 \\
\hline Endometrial hyperplasia & 12 & 6 \\
\hline & 200 & 100 \\
\hline
\end{tabular}

The most commonly occurring change was found to be proliferative phase $(60 \%)$.

Table 5: Endometrial changes in DUB in relation to age

\begin{tabular}{|l|c|c|c|c|c|c|}
\hline Age group & $\begin{array}{c}\text { Proliferative } \\
\text { phase }\end{array}$ & $\begin{array}{c}\text { Secretory } \\
\text { phase }\end{array}$ & Atrophic & $\begin{array}{c}\text { Irregular } \\
\text { shedding }\end{array}$ & $\begin{array}{c}\text { Irregular } \\
\text { ripening }\end{array}$ & $\begin{array}{c}\text { Endometrial } \\
\text { hyperplasia }\end{array}$ \\
\hline 18 to 28 & 4 & 7 & & & 7 & 2 \\
\hline 29 to 38 & 6 & 14 & 2 & 1 & 4 & 3 \\
\hline 39 to 50 & 70 & 19 & 14 & 15 & 25 & 7 \\
\hline & 80 & 40 & 16 & 16 & 36 & 12 \\
\hline
\end{tabular}

\section{Discussion}

The majority of the cases of DUB were in the age group of 39 to 45 years $(75 \%)$ with proliferative phase $(40 \%)$ as the dominant histopathological pattern followed by secretory phase (20\%) which was in accordance with L Sushila Devi ${ }^{9}$ et al who studied endometrium in 50 cases of DUB \& 10 normal cases. They found that $54 \%$ of patients belonged to 36-45 years age. They found endometrial pattern was proliferative (44\%), secretory (20\%), irregular ripening (14\%), atrophic endometrium (18\%), irregular shedding
(4\%). They concluded that commonest types of endometrium in DUB are proliferative and secretory types, also Riaz et $\mathrm{al}^{10}$ studied 100 patients in 35-50 years age group with menorrhagia and subjected them to curettage and studied endometrial histopathology. They found that $67 \%$ cases were above 40 years. Proliferative endometrium was obtained in $33 \%$ cases, secretory endometrium in $26 \%$, cystic hyperplasia in $25 \%$ and $\mathrm{CA}$ endometrium in one case. Cystic hyperplasia and proliferative endometrium were found above 40 years of age9. Menorrhagia (46\%) 
was the most common type of bleeding followed by polymenorrhia (24\%) in our study which is in accordance (Zeeba et al) ${ }^{11}(41 \%)$ and (Moghal et al) ${ }^{12}(41 \%)$ and was less as compared to (Yusuf et al) ${ }^{13}(69.65 \%)$ and (Muzaffar et al) ${ }^{14}(51.9 \%)$ [20]. Several studies have reported that endometrial hyperplasia is more common observation like Muzaffer et al ${ }^{14}$ studied curetting of 260 patients of DUB in age group of 21-50 years obtained by D\&C and pathology was found in $40 \%$ of all biopsies with endometrial hyperplasia (24\%), chronic non-specific endometritis (13\%), endometrial polyp (1.2\%), pill pattern endometrium (2.3\%), atrophic endometrium $(0.8 \%)$, menopausal pattern endometrium, squamous metaplasia, squamous cell carcinoma $(0.4 \%)$. Most patients belonged to 41-50 year age group but in our study it was only $6 \%$ but none of them had endometrial carcinoma ,out of 12 patients 7 were in age group 39 to 50 years so it mandates to do curettage in perimenopausal women as it may lead to endometrial carcinoma.

\section{Conclusion}

Anovulation is commonest cause of AUB in reproductive age group and study of histopathological changes of endometrium is very important in management of AUB. The present study revealed that proliferative endometrium is the most common endometrial histopathological patterns in endometrial samples obtained for abnormal uterine bleeding in our region. All patients having abnormal menstrual bleeding should be subjected to dilatation and curettage to rule out endometrial pathology. Accurate analysis of endometrial sample is the key to effective therapy and rational approach to treatment of women with abnormal uterine bleeding. Thus, histopathological evaluation of endometrium is especially indicated in women over the age forty years to rule out preneoplastic lesions and malignancies.

\section{References}

1. Goldstein SR. Menorrhagia and abnormal bleeding before themenopause. Best Pract Res Clin Obstet Gynaecol 2004;18:59-69.

2. Cornitescu FI, Tãnase F, Simionescu C, Iliescu D. Clinical, histopathological and therapeutic considerations in nonneoplastic abnormal uterine bleeding in menopause transition. Rom J Morphol Embryol 2011; 52:759-65.

3. ACOG Committee on Practice Bulletins Gynecology.ACOG Practice Bulletin No. 14: management of anovulatory bleeding. Int'l J Gynaecol Obstet 2001; 72: 263-71.

4. Albers JR, Hull SK, Wesley RM. Abnormal uterine bleeding. Am Fam Physician 2004; 69: 1915-26.

5. Spencer CP, Whitehead MI. Endometrial assessment re-visited. $\mathrm{Br} \quad \mathrm{J}$ Obstet Gynaecol 1999; 106: 623-32.

6. Hemalatha AN, Pai MR, Raghuveer CV. Endometrial aspiration cytology in dysfunctional uterine bleeding.Indian $\mathbf{J}$ Pathol Microbiol. 2006 Apr; 49(2):214-7.

7. Munro MG, Critchley HO, Broder MG, Fraser IS. FIGO recommendations on terminologies and definition for normal and abnormal uterine bleeding. International Journal of Gynecology and Obstetrics 2011; 113: 3-13.

8. Bhosle A, Fonseca M. Evaluation and histopathological correlation of abnormal uterine bleeding in perimenopausal women. Bombay Hosp J 2010;52:69- 72.

9. Sushila DL et al. The histological and histochemical study of endometrium in DUB. Journal of Medical Society (publication of RIMS, Imphal), 2012, 26(3):167-70.

10. Riaz S, Ibrar F, Dawood NS, Jabeen A. Endometrial pathology by endometrial curettage in menorrhagia in premenopausal age group. J Ayub Med Coll Abbottabad. Jul-Sep 2010; 22(3):1614. 
11. Zeeba Jairajpuri, Rana S, Jetley S. Atypical uterine bleeding

Histopathological audit of endometrium A study of 638 cases. Al Ameen J Med Sci 2013; 6(1): 21-8.

12. Moghal N. Diagnostic value of endometrial curettage in abnormal uterine bleeding - A histopathological study. J Pak Med Assoc 1997; 47: 295-9.

13. Yousuf NW, Nadeem R et al. Dysfunction uterine bleeding .A retrospective clinicopathological study over 2 years. Pak J Obstet Gynaecol.1996;9:27-30

14. Mohd. Muzaffar et al. Menstrual irregularities with excessive blood loss: a clinico-pathological correlation. JPMA. Nov 2005; 55(11): 486. 